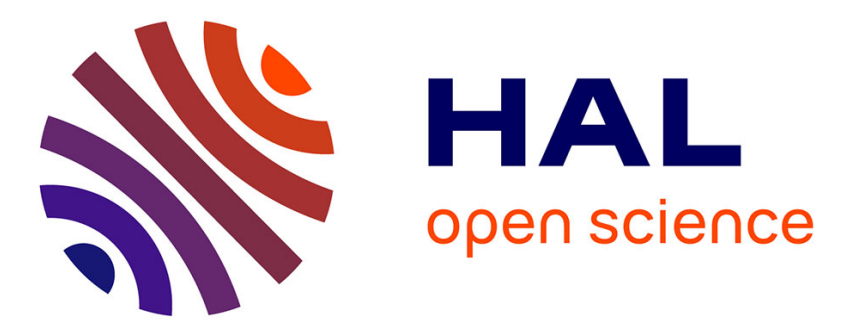

\title{
What factors influence the stem taper of Eucalyptus: growth, environmental conditions, or genetics?
}

Hugues Gomat, Deleporte, Moukini, Mialounguila, Ognouabi, Aubin Saya, Vigneron, Saint-Andre

\section{- To cite this version:}

Hugues Gomat, Deleporte, Moukini, Mialounguila, Ognouabi, et al.. What factors influence the stem taper of Eucalyptus: growth, environmental conditions, or genetics?. Annals of Forest Science, 2011, 68 (1), pp.109-120. 10.1007/s13595-011-0012-3 . hal-00930689

\section{HAL Id: hal-00930689 \\ https://hal.science/hal-00930689}

Submitted on 1 Jan 2011

HAL is a multi-disciplinary open access archive for the deposit and dissemination of scientific research documents, whether they are published or not. The documents may come from teaching and research institutions in France or abroad, or from public or private research centers.
L'archive ouverte pluridisciplinaire HAL, est destinée au dépôt et à la diffusion de documents scientifiques de niveau recherche, publiés ou non, émanant des établissements d'enseignement et de recherche français ou étrangers, des laboratoires publics ou privés.

$$
\text { Copyright }
$$




\title{
What factors influence the stem taper of Eucalyptus: growth, environmental conditions, or genetics?
}

\author{
Hugues Yvan Gomat • Philippe Deleporte • Régis Moukini • Gladys Mialounguila • \\ Nina Ognouabi • Aubin Rachel Saya • Philippe Vigneron • Laurent Saint-Andre
}

Received: 30 November 2009 / Accepted: 17 April 2010/Published online: 15 February 2011

(C) INRA and Springer Science+Business Media B.V. 2011

\begin{abstract}
- Introduction Stem taper equations have been widely used for volume estimation to varied top diameter limits or for biomass calculations. However, their main drawback is that specific calibration is often necessary for each species or clone, and accounting for genetic and environmental effects is often a challenge.

- Methods In order to investigate this point, we decided to study the stem shape of several clones growing in Congo and to build an equation which should (1) be simple and have a good predictive quality, (2) have explicit parameters, and (3) be generic enough so as to be transposable to other species or to other eucalyptus clones. A sample of 1,623 trees, representing 16 genetically different clones selected for their contrasting growth patterns, was used.
\end{abstract}

Handling Editor: Barry Gardiner

H. Y. Gomat $(\bowtie) \cdot$ G. Mialounguila $\cdot$ N. Ognouabi · A. R. Saya Centre de Recherche sur la Durabilité et la Productivité des Plantations Industrielles (CRDPI, ex UR2PI), BP 1291, Pointe-Noire, Republic of the Congo e-mail: biblio_gomat@yahoo.fr

P. Deleporte $\cdot$ L. Saint-Andre

CIRAD, UPR 80, Ecosystèmes de Plantation,

34398 Montpellier, France

R. Moukini

Eucalyptus Fibre du Congo SA,

BP 682, Pointe-Noire, Republic of the Congo

P. Vigneron

CIRAD, UPR 39, Génétique forestière,

34398 Montpellier, France

L. Saint-Andre

INRA, Unité Biogéochimie des Ecosystèmes Forestiers,

54280 Champenoux, France
- Results Even though these clones had different stem shapes, we successfully developed a single equation using the triplet (height/diameter at breast height/age) for all the clones.

- Conclusions The study also indicates that both growth environmental conditions and genetics have an impact on the stem shape, but that the genetic effect was fully realized through tree growth. The root mean square error for the over-bark diameter was $7 \mathrm{~mm}$, allowing its use over the whole plantation area.

Keywords Stem form - Taper equation - Stem volume · Generic equation $\cdot$ Congo $\cdot$ Eucalyptus .

Continuous equation

\section{Introduction}

Assessing the ring increments along the tree bole, the volume, or the biomass of a tree is of major importance for forest managers. The knowledge of these variables and their variations with stand age, thinning intensities (if any) or the fertilisation regime is crucial for harvest scheduling in a given forest area (Bi and Turner 1994). Stem taper equations are useful for such purposes, and they have been intensively studied during the last 40 years. Several reviews can be found in Newnham (1988), Bi (2000), and Valentine and Gregoire (2001). The main advantage of these equations compared to volume tables is their flexibility. Using a single taper function, diameters and volumes can be estimated at any height within the tree, and when rearranged, the height to a given top end diameter can be estimated. The first taper equations were probably published by Höjer (1903) in Demaerschalk (1971), and Behre (1923), but Newnham's work in 1958 (in Newnham 1965) marks the real starting point for their development. He showed that a quadratic parabola fitted well the bole shape of Douglas fir (Pseudot- 
suga menziesii Mirb.), Western hemlock (Tsuga heterophylla (Raf.) Sarg.), and Western red cedar (Thuja plicata Donn.). His Eq. 1 was simple, and parameters could be easily estimated through multiple regression analysis.

$d_{h}^{2}=a+b \cdot h$

where $a$ is the square diameter at the tree base, and $b$ is an index of the bole taper.

Since then, several types of equations have been tested for most of the species growing in managed tropical and temperate forests: polynomial (Bruce et al. 1968; Demaerschalk 1971; Real and Moore 1988), trigonometric (Thomas and Parresol 1991), variable form exponent (Ormerod 1973; Forslund 1982; Newnham 1988; Kozak 1988, etc.), and switching bole taper equation (Valentine and Gregoire 2001). This huge amount of literature demonstrates the difficulty of developing accurate and flexible functions that can fit to many tree species. Generally, the final models have many parameters with a low biological meaning ( $\mathrm{Bi} 2000$ ). This lack of generality is a real drawback for such equations, and keeping the idea of the variable form exponent, $\mathrm{Bi}(2000)$ chose a trigonometric function of relative height $\left(h_{r}\right)$ for the numerator instead of simply the height within the tree (Eq. 2).

$d_{h r}=\left(\frac{\ln \left(\sin \left(\left(\frac{\pi}{2}\right) \cdot h r\right)\right.}{\ln \left(\sin \left(\left(\frac{\pi}{2}\right) \cdot b\right)\right.}\right)^{k}$

where $k$ is a function of relative height $\left(h_{r}\right)$, total height $(H)$, and diameter at breast height (DBH).

His formulation gave much more flexibility to the taper equation. The model was less biased $(28 \%)$ and more precise $(7.4 \%)$ in predicting relative diameter than the classical Kozak's variable-exponent taper equation (1988) with similar number of parameters. The equation was successfully applied to different eucalyptus species and succeeded in replacing numerous site-specific equations for Pinus radiata (Bi and Long 2001).

The approach developed by Bi (2000) and Bi and Long (2001) has potential for the eucalyptus plantations in Pointe-Noire (Republic of the Congo) where a large number of genotypes were selected, and about 170 different clones have been planted on 43,000 ha of forest land. It will be practically impossible to develop a stem taper equation for each clone (or at least each full-sib family).

The objective of this study was to develop a single model that could be used irrespective of the genotype. We maintained the idea of Bi (2000) which states that the lack of flexibility of taper equations induces a lack in generality and that many site-specific equations could be replaced by a single model. However, because parameters of his model cannot be easily related to the different parts of the tree (butt swell, global taper, etc.), we decided to use our own equation which proved to be flexible enough in describing tree stem shape (Saint-André et al. 2002; Adu-Bredu et al. 2008). We hypothesised that differences between eucalypt clones can be fully explained by knowing age, height and diameter at breast height of the trees and that a single model, appropriately chosen, would be accurate enough whatever the genotype.

\section{Materials and methods}

\subsection{Fitting dataset}

A clone of the natural hybrid Eucalyptus PF1 (clone 1-41) and four clones of the hybrid Eucalyptus urophylla $\times$ Eucalyptus grandis (clones 18-50, 18-52, 18-69 and 1885 ) resulting from the same mother and the same father were selected for this study. Clone $1-41$ is the most widely planted and currently constitutes a control for all field experiments in Pointe-Noire (Republic of the Congo). It may have originated from a crossing between Eucalyptus alba (mother tree) with a poorly identified hybrid (father tree), which includes probably E. grandis, E. robusta, E. urophylla and $E$. botryoïdes. The clones of $E$. urophylla $\times E$. grandis came from artificial hybridization and genetic selections. They constitute the main part of the plantations since 2000 because of their high productivity $\left(40 \mathrm{~m}^{3} / \mathrm{ha} /\right.$ year in clonal test and $20 \mathrm{~m}^{3} /$ ha/year in plantations; Safou-Matondo et al. 2005) compared to Eucalyptus PF1 (clone 1-41) which has a maximum productivity of only $18 \mathrm{~m}^{3} /$ ha/year.

The sampling strategy covered the widest available range of plantation density and stand age for each clone (Table 1). For most of them, we succeeded in finding almost all age classes in the industrial forest area. But for the stand density, it was necessary to sample in different experimental plots so as to find other stand densities than those applied by forest managers (700 stems/ha and 800 stems/ha are common practices).

Two plots were randomly established far from the roads (about 50 to $100 \mathrm{~m}$ ) within each selected stand to avoid the border effect which may influence the shape of the trees. A plot was composed of nine aligned living trees, without exceptional defects. If a plot contained two trees with the same diameter at breast height or very small trees (originating from the regeneration of the previous stand or from restocking operations 1 or 2 months after plantation), its location was shifted a little along the planting line, and the new series of nine aligned and living trees was measured.

\subsection{Validation dataset}

We used data from 13 clones of a second generation clonal test (hybrid E. urophylla $\times$ E. grandis, clones 18-50, 18- 
Table 1 Number of sampled trees by clone, planting density classes and age classes

\begin{tabular}{|c|c|c|c|c|c|c|c|c|c|c|c|c|c|}
\hline \multirow[t]{2}{*}{ Clone } & \multirow[t]{2}{*}{ Trees/hectare } & \multicolumn{11}{|c|}{ Age (years) } & \multirow[t]{2}{*}{ Total } \\
\hline & & 1 & 2 & 3 & 4 & 5 & 6 & 7 & 8 & 9 & 10 & 11 & \\
\hline \multirow[t]{3}{*}{$1 \_41$} & 500 & 10 & 10 & 30 & 47 & 18 & 44 & & 17 & 14 & & & 190 \\
\hline & 700 & 34 & 34 & 25 & 24 & 12 & 4 & 34 & 18 & 18 & 18 & 15 & 236 \\
\hline & 800 & 52 & 27 & 48 & 22 & 112 & 15 & 36 & 36 & & 18 & & 366 \\
\hline \multirow[t]{2}{*}{$18 \_50$} & 700 & & & & 18 & & & 18 & 12 & 18 & & & 66 \\
\hline & 800 & & & 90 & 9 & 18 & 18 & & 18 & & & & 153 \\
\hline \multirow[t]{3}{*}{$18 \_52$} & 700 & & & & 18 & & & 18 & 12 & 18 & & & 66 \\
\hline & 800 & 10 & 28 & 46 & 28 & & 18 & 18 & 18 & 18 & & & 184 \\
\hline & 1,300 & & & & & 18 & & & & & & & 18 \\
\hline \multirow[t]{2}{*}{ 18_69 } & 700 & & 18 & & & & & 9 & & & & & 27 \\
\hline & 800 & & 18 & 36 & 18 & & 9 & 18 & & & & & 99 \\
\hline \multirow[t]{3}{*}{$18 \_85$} & 700 & & 36 & & & & & 18 & & & & & 54 \\
\hline & 800 & & & 54 & 18 & & & & & & & & 72 \\
\hline & 1,100 & & & & & 18 & 9 & & & & & & 27 \\
\hline Total & & 106 & 171 & 329 & 202 & 196 & 117 & 169 & 131 & 86 & 36 & 15 & 1,558 \\
\hline
\end{tabular}

52, 18-147, 18-209,18-154, 18-168, 18-181, 18-205, 18207, 18-208, 18-252, 18-309, 18-535). Trees were 6 years old, and the stand density was 800 trees/ha. The sample consisted of five trees per clone (selected in three diameter classes: small, medium and large) leading to a total of 65 trees for this dataset (Table 2).

\subsection{Tree measurements}

Eucalyptus plantations have been established in the coastal plains of Congo for 30 years. Rotation length ranges between 7 and 9 years to reach a typical average value of $25 \mathrm{~m}$ for the height and $15 \mathrm{~cm}$ for the diameter. These plantations produce pulp wood for the international market and charcoal (big branches, small trees) for the local one.

On each tree, total height was measured with the VERTEX IV dendrometer (Haglöf Sweden AB), and the circumference at breast height $(\mathrm{CBH})$ was measured with a tape. Each tree was harvested, branches removed and the stem was cut into $1 \mathrm{~m}$ (young trees, less than 3 years old) or $2 \mathrm{~m}$ lengths (for old trees). Circumference was measured with a tape at the top cross-section of each log. This

Table 2 Validation dataset

\begin{tabular}{|c|c|c|c|c|c|c|c|c|c|}
\hline Clone & Mother & Father & $\begin{array}{l}\text { Average } \\
\text { DBH }(\mathrm{cm})\end{array}$ & $\begin{array}{l}\text { Min DBH } \\
(\mathrm{cm})\end{array}$ & $\begin{array}{l}\text { Max DBH } \\
(\mathrm{cm})\end{array}$ & $\begin{array}{l}\text { Average } \\
\text { height }(\mathrm{m})\end{array}$ & $\begin{array}{l}\text { Min height } \\
\text { (m) }\end{array}$ & $\begin{array}{l}\text { Max height } \\
\text { (m) }\end{array}$ & $\mathrm{Nb}$ trees \\
\hline $18-50$ & $14-36$ & $9-10$ & 14.47 & 9.87 & 17.79 & 24 & 18 & 28 & 5 \\
\hline $18-52$ & & & 16.29 & 14.74 & 17.54 & 26 & 25 & 27 & 5 \\
\hline $18-252$ & & & 15.42 & 12.67 & 17.83 & 24 & 21 & 26 & 5 \\
\hline $18-154$ & $14-63$ & $9-21$ & 12.26 & 7.67 & 14.96 & 29 & 20 & 51 & 5 \\
\hline $18-168$ & & & 14.32 & 11.11 & 17.48 & 25 & 21 & 29 & 5 \\
\hline 18-207 & & & 16.11 & 12.32 & 19.61 & 25 & 20 & 28 & 5 \\
\hline 18-208 & & & 16.59 & 13.21 & 19.70 & 25 & 21 & 27 & 5 \\
\hline 18-209 & & & 17.73 & 13.59 & 20.53 & 26 & 19 & 28 & 5 \\
\hline 18-309 & & & 16.08 & 12.13 & 19.48 & 24 & 21 & 26 & 5 \\
\hline $18-147$ & $14-74$ & $9-21$ & 17.66 & 15.25 & 20.37 & 27 & 25 & 29 & 5 \\
\hline $18-181$ & $14-76$ & $9-21$ & 15.48 & 10.73 & 18.27 & 24 & 18 & 26 & 5 \\
\hline 18-205 & & & 15.64 & 8.66 & 18.14 & 26 & 19 & 28 & 5 \\
\hline $18-535$ & $14-137$ & $9-41$ & 16.30 & 11.49 & 18.65 & 23 & 19 & 25 & 5 \\
\hline Total & & & 15.75 & 7.67 & 20.53 & 25 & 18 & 51 & 65 \\
\hline
\end{tabular}


adaptive sampling procedure allowed a slight correction of the imbalance between young and old trees without the constraints of a percentage sampling strategy which is better for stem taper fittings but difficult to apply in the field. On average, this resulted in 17 measurements per tree for the young stands and 21 measurements per tree for the old ones. Log volume was obtained from the truncated cone formula, and tree volume was calculated as the sum of $\log$ volumes.

\subsection{Model formulation}

We used the model developed by Saint-André et al. 2002 for the clone PF1 1-41. This equation has great flexibility and was recently used by Adu-Bredu et al. (2008) for teak trees. Each part of the equation describes the shape of each section of the stem: the parameters are thus interpretable and give a biological significance compared to the traditional stem profile models. The equation is of the form:

$d r=d_{h r} / D B H=a \cdot\left[\left(1-b h_{r}\right) \cdot\left(1+c \cdot e^{-d \cdot h r}\right)-(1-b) \cdot h_{r}^{e}\right]$

where $d r$ is the relative diameter (diameter of the crosssection divided by DBH), $h_{r}$ is the relative height (height of the cross-section divided by tree height), $a$ and $b$ give the general taper of the tree, $c$ and $d$ drive the taper of the buttswell, and $e$ controls the stem shape at the top of the tree. We studied the relative diameter as a function of relative height in order to remove most of size and growth rate effects on the tree profile.

\subsection{Model fitting}

We first performed an exploratory stage to find the appropriate model using PROC NLIN of SAS/STAT package (SAS ${ }^{\circledR}$ Institute Inc., Cary, NC, USA, 2004) and ordinary least square optimization. This step consisted of fitting parameters $a, b, c, d$ and $e$ of Eq. 3 for the whole dataset, for each clone and then for each tree. The objective was (1) to analyse the correlation between the individual tree parameters with the various tree and stand variables like tree height $(H), \mathrm{DBH}$, the ratio of tree height to DBH (HSD), stand age (AGE), tree's hardiness $\left(\mathrm{ROB}=\mathrm{CBH}^{1 / 2} / H\right.$, see Vallet et al. (2006) for the description of this variable) and stand density; (2) to study the form of the relationship identified thereof (e.g. linear, power and exponential functions); and then (3) to incorporate the relationship into the model to obtain a global stem profile model.

The final stage consisted of fitting this global model with PROC MODEL of SAS/ETS package and full information maximum likelihood estimation (FIML). A second-order autoregressive error structure was introduced to account for autocorrelations between residuals (e.g. Anta et al. 2007). A model for the variance was also tested to account for heteroscedasticity. The error component was proportional to a surrogate of tree volume raised to a power $k$ (Eq. 4).

$\operatorname{Var}(\varepsilon)=\sigma^{2}\left(D B H^{2} \times H\right)^{2 k}$

Genotype effects on this final model were assessed by checking error distributions and by performing an ANOVA on the model error. The overall deviation was measured by the mean residual (ideal value being zero). Indices of model precision were given by the computation of root mean square error (RMSE) and modelling efficiency (EF, Mayer and Butler 1993) with the ideal value being, respectively, 0 and 1. The predictive performance of the model was assessed using bootstrap methods. We used the aggregate prediction error (APE) proposed by Davison and Hinkley (1997) where the core dataset is divided into a training set encompassing $90 \%$ of the data and a validation set including the remaining $10 \%$. The set of equation was fitted 100 times, and the APE was calculated as follows (Eq. 5):

$A P E=\frac{1}{100} \sum_{r u n=1}^{100} \frac{1}{n_{v}} \sum_{i=1}^{n_{v}}(y-\widehat{y})^{2}$

where $n_{v}$ is the number of diameter values used for the validation, $y$ is the observed diameter values, and $\hat{y}$ is the simulated ones. EF was also calculated for each fit.

Lastly, the final equation was applied to the validation set, and the performance in predicting both diameter along the tree bole and total tree volume was assessed by the abovementioned criteria (deviation, RMSE and EF).

\section{Results}

The tree shape changes markedly between 1 and 2 years and then is roughly stabilised afterwards (Fig. 1a, b). From 3 years onwards, the buttresses increase with stand age. On average, planting density (for the current range of variation) has no significant influence on the stem profile (Fig. 1c). The global form of the trees remains the same between clones whatever the stand age and the stand density, although some slight differences can be observed (Fig. 1d).

\subsection{Initial global model}

Equation 3 was fitted to the whole dataset. The performance of this initial global model was good, with an RMSE of 0.056 

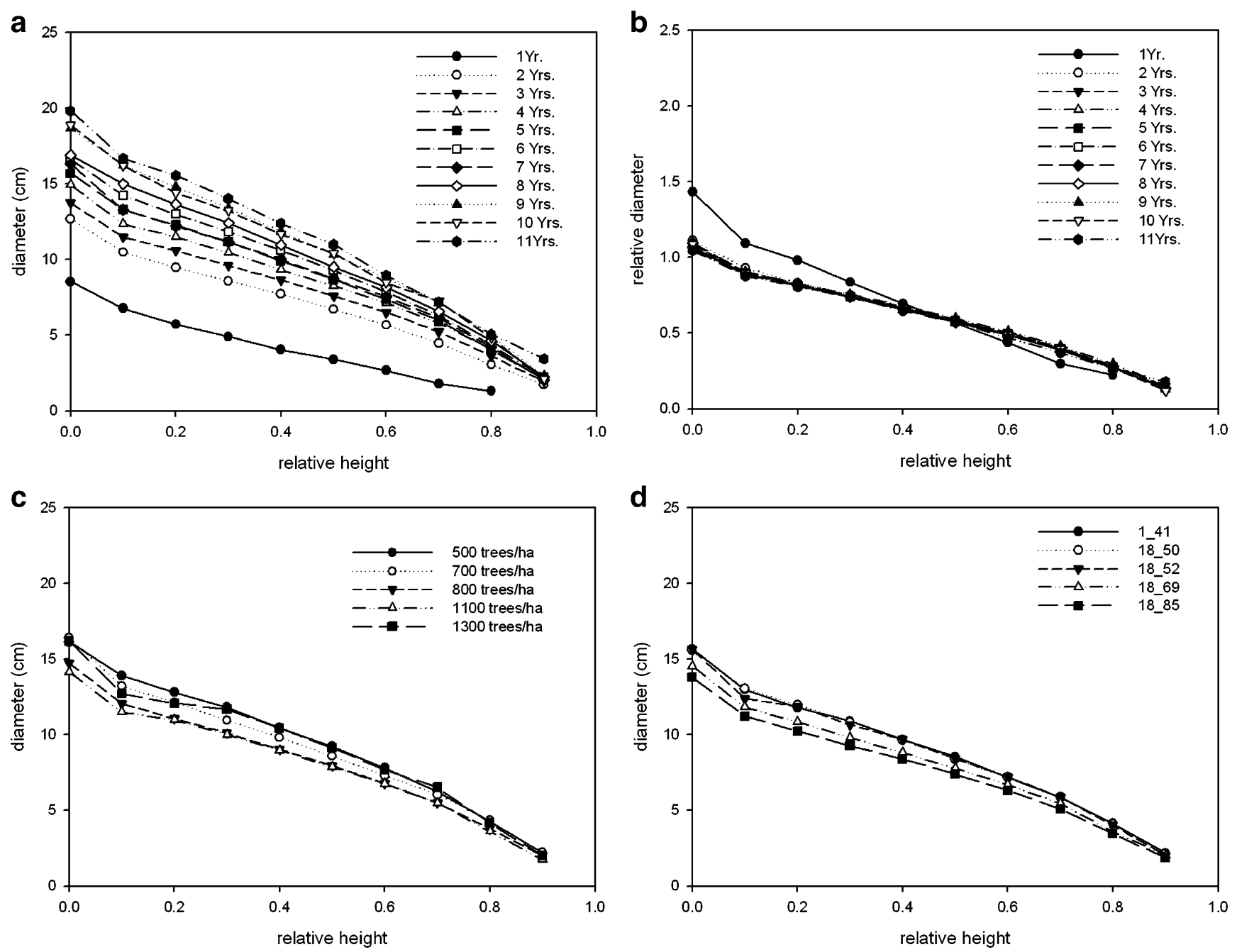

Fig. 1 Average stem profile. a, b Variation with stand age (all clones and stands densities pooled together). c Variation with stand densities (all clones and stands densities pooled together). d Variation with clones (at 7 years, stand densities of $700 \mathrm{stems} / \mathrm{ha}$ )

(5.6\% of the relative diameter) despite a significant slight bias: the slope of the relationship between the measured and the simulated relative diameter was equal to 0.97 and significantly different from 1. All parameters were significantly different from zero, and the global tapering of the tree bole was well reproduced (Fig. 2). There was a clone effect on this model $\left(F\right.$ obs $=5.70>F \operatorname{tab}_{10,1,543}=1.84$, classical $F$ test for nested models: one equation per clone versus one equation for all clones; Table 3).

\subsection{Initial individual model}

The tree by tree fit to the basic model Eq. 3 gave unbiased residuals. Despite the high variability in tree stem shape, the model performed well and was able to fit to any tree shape as illustrated in Fig. 2: neloidic in the young ages (Fig. 2a) then more cylindrical at harvest (Fig. 2b). The RMSE were respectively 0.0328 and 0.0147 for these two trees. When the whole dataset was considered, there were no statistical differences between clones for the parameter distributions. However, when the sampled trees were separated by age classes or by density classes, some differences could be observed between clones. Unfortunately, these differences were difficult to interpret, and no general pattern could be identified.

\subsection{Final global model}

To obtain the final formulation of the model, we analysed the correlation between the individual tree parameters regardless of the clone. We found a clear exponential age effect on parameters $a$ and $b$ (Fig. 2c, d) which both drive the global tapering of the tree (Fig. 1). We also found a height effect on $c$ which controls the buttress magnitude (Fig. 2e). Step by step, we then introduced secondary factors by comparing the predicted parameter values to the ones obtained during the individual model fitting. Prediction of parameter $a$ was then improved by introducing HSD and ROB; $b$ was also related to $\mathrm{DBH}, c$ to $\mathrm{AGE}$, and $d$ to ROB. However, introducing all 

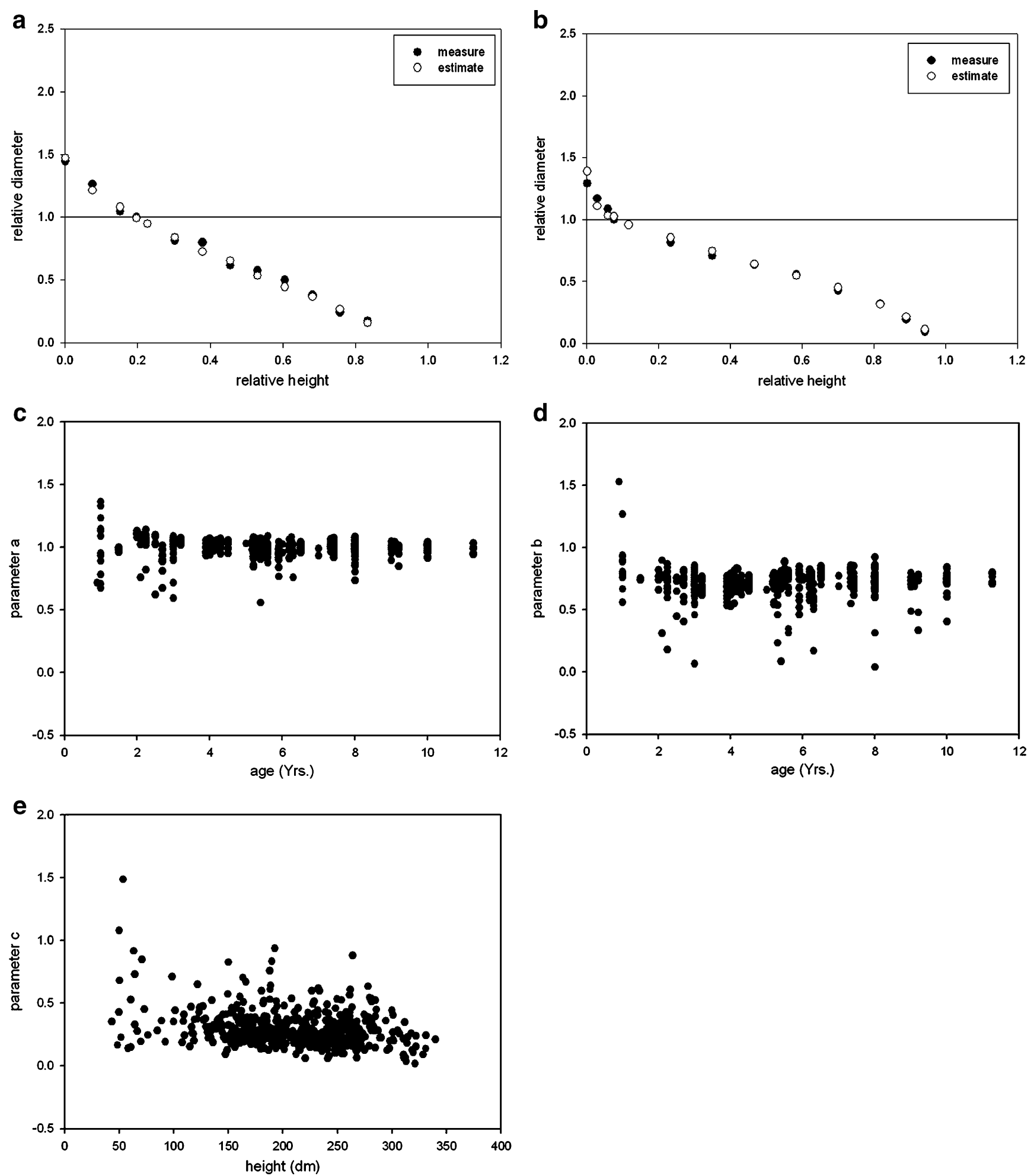

Fig. 2 Tree profile (measured and fitted) a for tree $n=50$ in plot 40,000, 1 year old; and b for tree $n=34$ in plot 4,019, 7 years. Parameter variations with tree and stand variables: $\mathbf{c}$ parameter $a$ according to age, $\mathbf{d}$ parameter $b$ according to age, and $\mathbf{e}$ parameter $c$ according to tree height

these sub-equations in Eq. 3 did not totally remove the bias observed previously the initial global model. A close look at the simulated parameter distributions showed that some combinations were not captured by the models. When the correlation between parameters was introduced in the equations (parameters $a$ and $b$ are direct functions of parameter $c$ ), the bias was totally removed. The slope between the measured diameters and the simulated ones was equal to 1 . The final 
Table 3 Parameter estimates and error for the initial global model with by clone

\begin{tabular}{|c|c|c|c|c|c|c|c|}
\hline \multirow[t]{2}{*}{ Parameter } & \multicolumn{2}{|c|}{ Global model } & \multirow[t]{2}{*}{$1-41$} & \multirow[t]{2}{*}{$18-50$} & \multirow[t]{2}{*}{$18-52$} & \multirow[t]{2}{*}{$18-69$} & \multirow[t]{2}{*}{$18-85$} \\
\hline & Estimated & Standard error & & & & & \\
\hline$a$ & 1.040 & 0.001 & 1.052 & 1.017 & 1.026 & 1.023 & 1.025 \\
\hline$b$ & 0.799 & 0.002 & 0.815 & 0.794 & 0.772 & 0.765 & 0.768 \\
\hline$c$ & 0.242 & 0.002 & 0.254 & 0.184 & 0.269 & 0.226 & 0.242 \\
\hline$d$ & 49.294 & 1.081 & 59.033 & 37.570 & 44.630 & 29.630 & 32.612 \\
\hline$e$ & 8.050 & 0.141 & 8.628 & 8.305 & 7.185 & 6.691 & 6.949 \\
\hline SSE & 95.130 & & 66.037 & 5.799 & 11.945 & 3.608 & 4.353 \\
\hline RMSE & 0.056 & & 0.066 & 0.034 & 0.048 & 0.038 & 0.040 \\
\hline Number measurements & 30,317 & & 14,938 & 4,952 & 5,132 & 2,497 & 2,798 \\
\hline Number trees & 1,558 & & 792 & 219 & 268 & 126 & 153 \\
\hline
\end{tabular}

model is given by Eq. 3 and the following expressions, with parameter values in Table 4:

$$
\begin{aligned}
a= & a 0+\left(a 1 \times \exp ^{(-a 2 \times A G E)}\right)-\exp ^{\left(-a 3 \times \frac{H S D}{240}\right)} \\
& +(a 4+a 5 \times A G E) \times(R O B \times 100)-a 6 \times c \\
b= & b 0+\left(b 1 \times \exp ^{(-b 2 \times A G E)}\right)-\left(b 3 \times \exp ^{(-b 4 \times D B H)}\right)+b 5 \times c \\
c= & c 0-\left(c 1 \times \exp ^{(-c 2 \times A G E)}\right)-c 3 \times H \\
d= & d 0 \times(1-(R O B \times 100)) \\
e= & e 0
\end{aligned}
$$

The RMSE of the final model was 0.036 (35\% better than the initial global model). All parameters were significantly different from zero with a low standard error ( $85 \%$ of the parameters had a coefficient of variation less than $10 \%$ ). Because of the high number of parameters, a particular attention was given to the parameter correlation matrix. Eighty-three percent of the correlations was below 0.2 , and only $3 \%$ was above 0.7 . We also checked if the model could be simplified (for example between $R O B$ and $H S D$ in a sub-model), but in all cases, $\mathrm{F}$ tests showed that the full model was preferable to the simplified ones: sum of square errors was systematically significantly higher in the simplified models. Errors were well spread around zero for AGE, DBH, HSD, ROB and genotype (Fig. 3). The

\begin{tabular}{|c|c|c|c|c|c|}
\hline Parameter & Value & Asymptotic standard error & Test $t$ & $\operatorname{Pr}>|t|$ & Variation \\
\hline $\mathrm{a} 0$ & 0.948 & 0.008 & 113.060 & $<0.0001$ & $0.9 \%$ \\
\hline a1 & 0.437 & 0.033 & 13.400 & $<0.0001$ & $7.5 \%$ \\
\hline a2 & 0.899 & 0.045 & 20.090 & $<0.0001$ & $5.0 \%$ \\
\hline a3 & 3.560 & 0.116 & 30.630 & $<0.0001$ & $3.3 \%$ \\
\hline $\mathrm{a} 4$ & 0.576 & 0.032 & 17.750 & $<0.0001$ & $5.6 \%$ \\
\hline a5 & 0.026 & 0.003 & 7.640 & $<0.0001$ & $13.1 \%$ \\
\hline a6 & 0.239 & 0.044 & 5.470 & $<0.0001$ & $18.3 \%$ \\
\hline b0 & 0.647 & 0.017 & 38.530 & $<0.0001$ & $2.6 \%$ \\
\hline b1 & 1.038 & 0.032 & 32.610 & $<0.0001$ & $3.1 \%$ \\
\hline b2 & 0.833 & 0.033 & 25.420 & $<0.0001$ & $3.9 \%$ \\
\hline b3 & 0.470 & 0.029 & 16.230 & $<0.0001$ & $6.1 \%$ \\
\hline b4 & 0.167 & 0.014 & 11.690 & $<0.0001$ & $8.5 \%$ \\
\hline b5 & 0.586 & 0.075 & 7.800 & $<0.0001$ & $12.8 \%$ \\
\hline $\mathrm{c} 0$ & 0.621 & 0.018 & 35.040 & $<0.0001$ & $2.8 \%$ \\
\hline $\mathrm{c} 1$ & 0.450 & 0.015 & 29.310 & $<0.0001$ & $3.4 \%$ \\
\hline $\mathrm{c} 2$ & 0.189 & 0.012 & 15.590 & $<0.0001$ & $6.4 \%$ \\
\hline c3 & 0.010 & 0.000 & 23.000 & $<0.0001$ & $4.4 \%$ \\
\hline d0 & 51.660 & 0.783 & 65.950 & $<0.0001$ & $1.5 \%$ \\
\hline $\mathrm{e} 0$ & 7.116 & 0.123 & 58.000 & $<0.0001$ & $1.7 \%$ \\
\hline
\end{tabular}
ANOVA indicated however that there was a significant
Table 4 Parameters of the final model for all the clones and variation of standard error on value estimate 

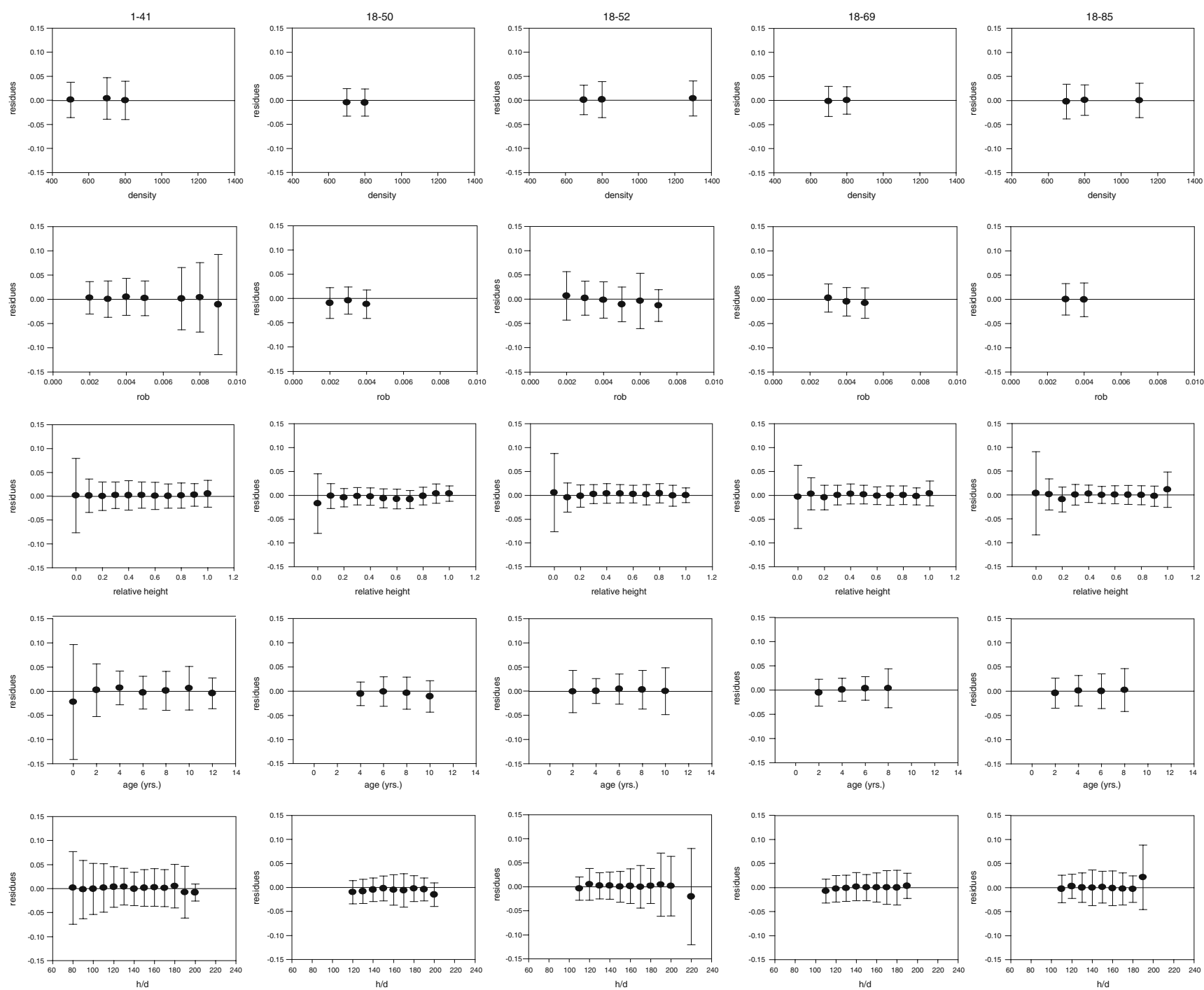

Fig. 3 Residuals according to the variables of the final model (DENSITY, ROB, relative height, $A G E, H S D$ )

clone effect on the residual errors $(F$ value $=27.65, p<$ $0.0001)$ mainly due to clone $18-50$. However, the magnitude of the deviations was limited for this clone $(-0.0046)$ and represented only $-0.73 \%$ of the average relative diameter (Table 5).

Risks of multicollinearity were limited since the condition number, which is defined as the square root of the ratio of the largest to the smallest eigenvalue of the correlation matrix, was relatively low (102) compared to some values reported by Diéguez-Aranda et al. (2006) and far below the value of 1,000-3,000 which was reported by Belsey (1991) to indicate severe problems of multicollinearity. The APE was found to be very close $(0.041)$ to the calibration RMSE, the EF ranged between 0.977 and 0.985 , and parameter variations among the 100 runs were low (on the average $4 \%$ of the parameter value). All these points confirmed the high robustness of the model.

\subsection{Validation}

Figure 4 displays the results obtained on the validation dataset for both the diameter along the tree bole and the total tree volume. The simultaneous $\mathrm{F}$ test for bias, slope $=1$ and intercept $=0$ was significant for the diameter $(F$ value $=$ $81.85, p<0.0001)$ and non-significant for the volume $(F$ value $=0.64, p=0.53$ ). The slope was close to 1 (respectively, 1.01 and 0.99 for the diameter and the volume). The absolute error distributions as a function of the relative height give close values to those obtained on the calibration dataset for all of the 13 clones (Fig. 5) except, in some cases, at the top of the tree. For clone 18-52 and 18-154, errors are higher than expected, but in both cases, it is due to one tree (among the five used in the validation dataset), and we suspect an error in the height measurement (possibly a broken top?). However, for all the 13 clones, 
Table 5 ANOVA on the residual errors of the final model

\begin{tabular}{llcccc}
\hline Source & DDL & Sum of squares & Mean square & $F$ value & $\begin{array}{l}\operatorname{Pr}>F \\
\text { Model }\end{array}$ \\
Error & 9 & 0.155 & 0.0172 & 13.15 & $<0.0001$ \\
Corrected total & 30,307 & 39.74 & 0.0013 & & \\
$R^{2}$ & 30,316 & 39.89 & & & \\
0.004 & & RMSE & Average errors & & \\
Source & DDL & Type III SS & Mean square & $F$ value & $\operatorname{Pr}>F$ \\
ROB & 1 & 0.00022 & 0.00022 & 0.17 & 0.68 \\
DENSITY & 1 & 0.00003 & 0.00003 & 0.03 & 0.87 \\
$H$ & 1 & 0.00465 & 0.00465 & 3.55 & 0.06 \\
AGE & 1 & 0.00092 & 0.00092 & 0.7 & 0.40 \\
HSD & 1 & 0.00046 & 0.00046 & 0.35 & 0.56 \\
Clone & 4 & 0.14502 & 0.03625 & 27.65 & $<0.0001$ \\
\hline
\end{tabular}

errors are very low (RMSE on the validation dataset was $6 \mathrm{~mm}$ and $0.016 \mathrm{~m}^{3}$ on the diameter and the volume, respectively). The EF was close to the maximum ( 0.98 for the diameter and 0.97 for volume), thus confirming the good performance of the model (Table 6).

\section{Discussion and conclusion}

\subsection{Mathematical and statistical aspects}

The basic equation (Eq. 3) differs from the traditional variable exponent-form function but succeeded in simulating very different shapes (especially the very young trees that are difficult to describe with traditional equations). The equation can be considered as a segmented model because each part of the tree is modelled by a dedicated function (Demearschalk and Kozak 1977; Max and Burkhart 1976). But our equation is also continuous in its mathematical formulation and thus provides great flexibility (Biging 1984; Adu-Bredu et al. 2008; Saint-André et al. 2002). This basic model (Eq. 3) was obtained after several and unsatisfactory trials using variable exponent-form equations where the main difficulty is to find an accurate function for the exponent and the final models have many parameters with a low biological meaning (Bi 2000). Another drawback was previously identified by Daquitaine et al. (2000): such equations are often constrained to equal the measured diameter at breast height, and this induces to a particular trend in the residual structure. This was not the case for our equation. Errors were well spread out around zero whatever the relative height and the genotype (Figs. 3 and 4).

\subsection{Biological aspects}

The main result of this study is that a single equation was suitable for all clones, despite high variations in growth patterns and nutrient use efficiencies (Safou-Matondo et al. 2005). This was obtained thanks to the flexibility of the equation and the use of biologically significant variables into each sub-model. This improved the accuracy of the model, and the introduced variables account for growth variations to each part of the stem (buttress, global tapering, top of the tree). Courbet and Houllier (2002) also showed that introducing slenderness or crown base height in the
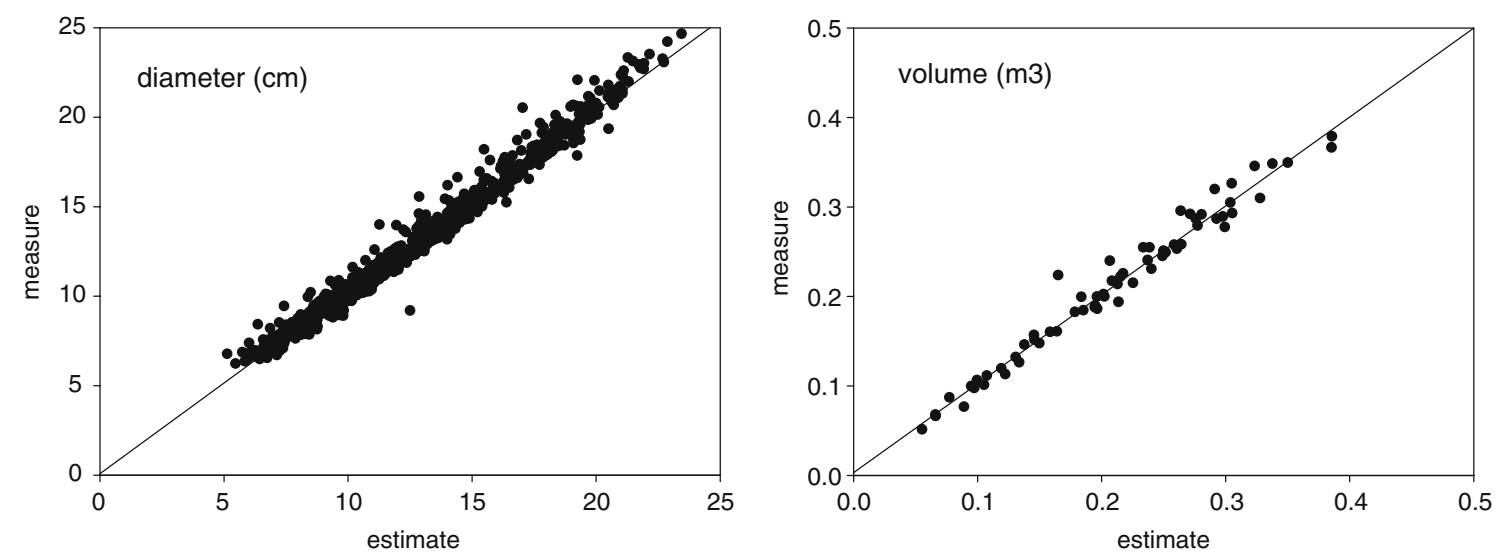

Fig. 4 Simulated compared to measured diameters and volumes for the validation sample 

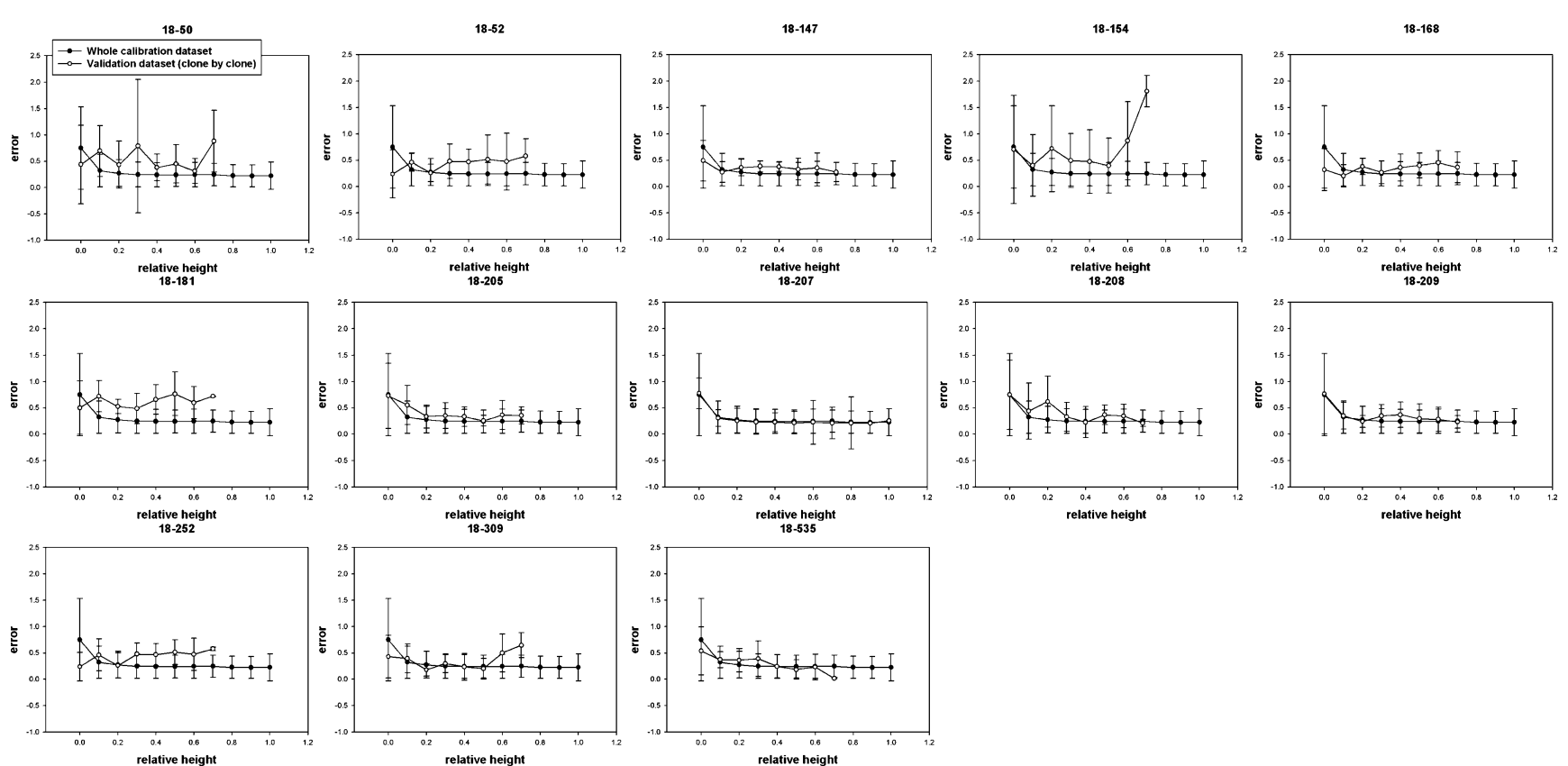

Fig. 5 Average absolute error on the diameter (centimetre) as a function of relative height for each of the 13 clones (black dots calibration dataset; white dots validation dataset)

equations improved the accuracy of stem profile predictions on Cedrus atlantica. Newton and Amponsah (2007) also demonstrated that the introduction of stand variables (such as a stand density index or the dominant height) improved the between tree height and diameter at breast height models (H-D equations). Similar result was obtained by

Table 6 Statistics for the whole validation sample

\begin{tabular}{lcc}
\hline & Diameter $(\mathrm{cm})$ & Volume $\left(\mathrm{m}^{3}\right)$ \\
\hline Number of observations & 779 & 65 \\
Mean (observed values) & 13.1 & 0.213 \\
Mean (simulated values) & 12.8 & 0.211 \\
Mean errors & -0.3 & -0.002 \\
Mean absolute errors (MAE) & 0.4 & 0.009 \\
Modelling efficiency (EF) & 0.976 & 0.972 \\
RMSE & 0.63 & 0.01 \\
MAE/mean (\%) & $3 \%$ & $4 \%$ \\
Linear regression & & \\
$R^{2}$ & 0.98 & 0.97 \\
Slope & $1.01^{*}$ & $0.99 \mathrm{~ns}$ \\
Intercept $^{\mathrm{a}}$ & $0.09 \mathrm{~ns}$ & $0.003 \mathrm{~ns}$ \\
Bias $^{\mathrm{b}}$ & $81.55^{* * *}$ & $0.64 \mathrm{~ns}$ \\
\hline
\end{tabular}

ns: $p>0.05$

$* p<0.05 ; * * * p<0.001$

${ }^{\mathrm{a}}$ Parameter value and $\operatorname{Pr}>F$ (intercept $\neq 0$ or slope $\neq 1$ )

${ }^{\mathrm{b}}$ Result of the simultaneous test of bias (intercept $\neq 0$ and slope $\neq 1$ ), $F$ value and $\operatorname{Pr}>F$
Saunders and Wagner (2008) after introducing stand density and basal area in H-D equations of nine different species in Northeastern United States. Conversely, Benbrahim and Gavaland (2003) found different stem taper parameters between two poplar hybrid clones, despite non-significant differences in diameter and total tree height. Jiang et al. (2005) also found significantly different parameters between regions for yellow-poplar taper and volume equations in West Virginia. Zakrzewski and MacFarlane (2006) found also regional differences for red pine equations in Michigan and Ontario. However, in all these cases, no attempt was made to introduce other tree characteristics such as age, slenderness or hardiness in the equations to account for species or regional differences as was done by Vallet et al. (2006) for volume equations for seven species in France. In our study, parameters $a$ and $b$, which drive the global tapering of the tree, were found to be correlated with AGE, HSD and tree's hardiness (ROB). Trees get more and more cylindrical as they grow, and for a given stand age, dominant trees are more tapered than suppressed ones. HSD and ROB both entered significantly in the $a$ submodel despite their high cross-correlation $(r=0.6)$, and they both are representative of effects of the tree social status. But in addition, we think that HSD accounts for stand density impacts on stem form, whereas ROB accounts for individual stem form variations (it was used by Vallet et al. 2006 to separate coppice and high forest trees). It would be interesting to test this equation on mixed stands (such as Acacia-Eucalyptus, Laclau et al. 2008) in order to verify that these two variables would succeed in dealing with the 
changes in growth patterns induced by the mixture (see for example del Rio and Sterba 2009; Laclau et al. 2008). Parameters $c$ and $d$, which control the buttressing, were found to be correlated with tree height, age and tree hardiness. Finally, the buttress is finally more pronounced for old and suppressed trees. When all these submodels were incorporated in Eq. 3, the clone effect was globally cancelled, meaning that the differences in stem form observed between clones at a given age, originated only from differences in tree growth. There was no need to incorporate an additional clone effect in the final model as demonstrated by the results from the validation dataset. As a conclusion, both tree growth, environmental conditions and genetics have an impact on stem shape, but for our tested eucalyptus clones, we demonstrated that the genetic effects were fully transmitted through tree growth.

\subsection{Practical use for the forest manager}

We believe that our equation is suitable for extended use in the plantations in Congo because (1) the performance of the final model was satisfactory for all clones (RMSE of about $4 \%$ in relative diameter which represents, or $7 \mathrm{~mm}$ in absolute diameter), (2) a comparison between the estimated and the measured volumes showed no deviation irrespective of genotype, (3) from the parameter analysis (standard error and correlation matrix), we can see that the final model is stable, and (4) the model uses relative height and relative diameter (ranging from 0 to 1 ), and the risk of simulating aberrant values is limited (this point is important when the model has to be applied outside the range of calibration). The main drawback of the model relates to its complex structure and the absence of a closed form integral for use in volume estimation. This means that the volume assessment has to be done using a specific iterative programme. However, this disadvantage is compensated for by the flexibility of the function that can provide diameters and volumes at any height or any top end diameter. Furthermore, because it works for the most contrasting clones planted in the forest area, the forest manager now has a single tool instead of having to rely on several equations (at least one for each clone and for each class of top end diameter for the previous volume-tables).

\footnotetext{
Acknowledgements We acknowledge the staff of Eucalyptus Fibre du Congo SA for the field work and Centre de Recherche pour la Durabilité des Plantations Industrielles (CRDPI ex UR2PI) for financial support. This study was also funded by the European Integrated Project Ultra Low CO2 Steelmaking (ULCOS - Contract no. 515960) and the EU project STREP-CARBOAFRICA (No. 037132). The language was kindly revised by Gregory van der Heijden. We also thank the two reviewers for the fruitful comments and language revision that improved the manuscript.
}

\section{References}

Adu-Bredu S, BI AFT, Bouillet J-P, Me MK, Kyei SY, Saint-Andre L (2008) An explicit stem profile model for forked and un-forked teak (Tectona grandis) trees in West Africa. For Ecol Manag 255:2189-2203

Anta MB, Dieguez-Aranda U, Castedo-Dorado F, Álvarez-González JG, Von Gadow K (2007) Merchantable volume system for pedunculate oak in northwestern Spain. Ann For Sci 64:511520

Behre CE (1923) Preliminary notes on studies of tree form. J Forest 21:507-511

Belsey DA (1991) Conditioning diagnostics, collinearity and weak data in regression. Wiley, New York

Benbrahim M, Gavaland A (2003) A new stem taper function for short-rotation poplar. Scand J For 18:1-7

Bi HQ (2000) Trigonometric variable-form taper equations for Australian Eucalypts. For Sci 46(3):397-409

Bi HQ, Turner J (1994) Long-term effects of superphosphate fertilization on stem form, taper and stem volume estimation of Pinus radiate. For Ecol Manage 70:285-297

Bi HQ, Long YS (2001) Flexible taper equation for site-specific management of Pinus radiata in New Wales. Australia For Ecol Manag 148:79-91

Biging GS (1984) Taper equations for second-growth mixed conifers of northern California. For Sci 4(30):1103-1117

Bruce R, Curtis L, Van Coevering C (1968) Development of a system of taper and volume tables for red alder. For Sci 14:339-350

Courbet F, Houllier F (2002) Modelling the profile and internal structure of tree stem. Application to Cedrus atlantica (Manetti). Ann For Sci 59:63-80

Daquitaine R, Saint-André L, Leban J-M (2000) Improve stem taper and ring width modelling based on standard tree measurements. Proc. Product properties prediction-improved utilization in forestry wood chain applied on spruce sawnwood, Project Fair CT96-1915, Final report of Sub-task 2.1, Leban J-M and Hervé J-C (ed) pp 3-23

Davison AC, Hinkley DV (1997) Bootstrap methods and their application. Cambridge University Press p 582

del Rio M, Sterba H (2009) Comparing volume growth in pure and mixed stands of Pinus sylvestris and Quercus pyrenaica. Ann For Sci 66:502, $11 \mathrm{p}$

Demaerschalk JP (1971) Taper equations can be converted to volume equations and point sampling factors. Forest Chron 47(6):352-354

Demearschalk JP, Kozak A (1977) Whole-bole system-conditioned dual-equation system for precise prediction of tree profiles. Can J For Res 7(3):488-497

Diéguez-Aranda U, Castedo-Dorado F, Álvarez-González JG, Rojo A (2006) Compatible taper function for Scots pine plantations in northwestern Spain. Can J For Res 36:1190-1205

Forslund RR (1982) A geometrical tree volume model based on the location of the centre of gravity of bole. Can J For Res 12 (2):215-221

Höjer AG (1903) Tallens och granens tillvaxt. Bihang till Pr. Loven. Om vara barrskogar. Stockholm

Jiang L, Brooks JR, Wang J (2005) Compatible taper and volume equations for yellow-poplar in West Virginia. For Ecol Manag 213:399-409

Kozak A (1988) A variable-exponent taper equation. Can J For Res 18:1363-1368

Laclau J-P, Bouillet J-P, Gonçalves JLM, Silva EV, Jourdan C, Cunha MCS, Moreira MR, Saint-André L, Gonçalves MR, Maquère V, Nouvellon Y, Ranger J (2008) Mixed-species plantations of Acacia mangium and Eucalyptus grandis in Brazil. 1. Growth dynamics and net primary production. For Ecol Manage 255:3905-3917 
Max TA, Burkhart HE (1976) Segmented-polynomial regression applied to taper equations. For Sci 22:283-289

Mayer DG, Butler DG (1993) Statistical validation. Ecol Model 68:21-32

Newnham RM (1965) Stem form and the variation of taper with and thinning regime. Forestry 38:218-224

Newnham RM (1988) A variable-form taper function. Can. For. Serv. Petawawa Natl. For. Inst. Inf. Rep. PI-X-83

Newton RF, Amponsah IG (2007) Comparative evaluation of five height-diameter models developed for black spruce and jack pine stand-types in terms of goodness-of-fit, lack-of-fit and predictive ability. For Ecol Manag 247:149-166

Ormerod DW (1973) A simple bole model. Forest Chron 49:136-138

Real PL, Moore JA (1988) An individual stem taper system for Douglas-fir in the inland north-west. In: Ek AR, Shifley SR, Burk TE (eds) Forest growth modelling and prediction. Proceeding of IUFRO Conference, 24-28th August 1987, Minneapolis, Minnesota. USDA Forest service General Technical Report NC120, pp 1037-1044

Safou-Matondo R, Deleporte P, Laclau J-P, Bouillet J-P (2005) Hybrid and clonal variability of nutrient content and nutrient use efficiency in Eucalyptus stands in Congo. For Ecol Manag 210:193-204
Saint-André L, Bouillet J-P, Deleporte P, Mabiala A, Ognouabi N, Baillières H, Nouvellon Y, Moukini R (2002) Integrative modelling approach to assess the sustainability of the eucalyptus plantations in Congo. In Proc. 4th Workshop on 'Connection between Forest Resources and Wood Quality: Modelling Approaches and Simulation Softwares'. Harrison Hot Springs Resort, British Columbia, Canada, September 815, 2002, pp 611-621

Saunders M, Wagner R (2008) Height-diameter models with random coefficients and site variales for tree species of Central Maine. Ann For Sci 65:203, 10 p

Thomas CE, Parresol BR (1991) Simple, flexible, trigonometric taper equations. Can J For Res 21:1132-1137

Valentine HT, Gregoire TG (2001) A switching model of bole taper. Can J For Res 31:1400-1409

Vallet P, Dhôte J-F, Le Moguédec G, Ravart M, Pignard G (2006) Development of total aboveground volume equations for seven important forest tree species in France. For Ecol Manag 229:98 110

Zakrzewski WT, MacFarlane DW (2006) Regional stem profile model for cross-border comparisons of harvested red pine (Pinus resinosa Ait.) in Ontario and Michigan. For Sci 52(4):468-475 